\title{
Research Note Economics analysis on yield of cotton as influenced by sulphur and micronutrients
}

\author{
N. MAMATHA AND H.S. RAMESH
}

See end of the paper for authors' affiliations

Correspondence to :

N. MAMATHA

Office of Assistant

Registrar of Cooperative

Societies, SHIMOGA

(KARNATAKA) INDIA

Email:mamathadavanagere@

gmail.com

Paper History :

Received : 12.08.2015:

Accepted : 27.02.2016

Cotton is still the principal commercial crop touching the country's economy at several points. It is also an important commercial crop of Karnataka and cultivated on an area of 4.78 lakh ha with a production of 6.77 lakh bales (Anonymous, 2003). With the introduction of high yielding and fertilizer responsive varieties, the practices of using large amounts of high analysis macronutrient fertilizers with much decreased use of organic manures and little recycling of crop residues led to micronutrient hunger in many crops. Generally the need of the micronutrients has been essentially and entirely met through its native reserve in the soil (Singh, 1999), Inspite of liberal application of N, P and K fertilizers, normal growth of high yielding varieties of crop could not be achieved due to little appreciation of the use of secondary and micronutrients.

High fertilizer responsive varieties can express their full yield potential only when limiting trace elements fertilizers are also applied along with NPK fertilizers.
Since, information on economic aspects of production of cotton (RAHB-87) is lacking in northern transitional zone (Zone-8) of Karnataka, the present study was carried out to know the optimum dose of nutrients, required to produce maximum yield which economically viable. A field experiment was conducted on medium black soil having initial organic carbon content of 0.58 per cent, $\mathrm{pH} 7.30$, available nitrogen phosphorus and potassium content of soil were $315,22.0,390 \mathrm{~kg} / \mathrm{ha}$, respectively. The experiment was laid out in randomized block design in 3 replications with nine treatment combinations.

Results revealed that treatment $\left(\mathrm{T}_{9}\right)$ receiving combined application of sulphur, iron, zinc each at $50 \mathrm{~kg}$ per ha recoded highest seed cotton yield ( $25.12 \mathrm{q} / \mathrm{ha})$ which was on par with treatment $\left(\mathrm{T}_{8}\right)$ receiving combined application of sulphur, iron and zinc each at $25 \mathrm{~kg}$ per ha. These two treatments were significantly superior over control. Economic analysis of the system revealed that, 